\title{
A Novel Injection-Molded Capsular Device for Oral Pulsatile Delivery Based on Swellable/Erodible Polymers
}

\author{
Andrea Gazzaniga, ${ }^{1,2}$ Matteo Cerea, ${ }^{1}$ Alberto Cozzi, ${ }^{1}$ Anastasia Foppoli, ${ }^{1}$ Alessandra Maroni, ${ }^{1}$ and Lucia Zema ${ }^{1}$
}

Received 31 July 2010; accepted 29 December 2010; published online 26 January 2011

\begin{abstract}
The feasibility of injection molding was explored in the preparation of a novel capsular device for oral pulsatile/delayed delivery based on swellable/erodible polymers. For this purpose, a mold intended to be coupled with a bench-top injection-molding press was designed. This was expected to enable the preparation of matching capsule cap and body items within a single manufacturing cycle and the selection of differing shell thicknesses $(300,600$, and $900 \mu \mathrm{m})$. Hydroxypropylcellulose (Klucel ${ }^{\circledR} \mathrm{EF}$, $\mathrm{LF}$, and GF) was employed as the release-controlling polymer in admixture with polyethylene glycol 1500 $(10 \%, w / w)$ as the plasticizer. After preliminary trials aimed at the setup of operating conditions, Klucel ${ }^{\circledR}$ EF and LF capsule shells with satisfactory technological properties were manufactured. The performance of capsular devices filled with a tracer drug powder was studied by means of a modified USP31 disintegration apparatus. Typical in vitro delayed release patterns were thereby obtained, with lag time increasing as a function of the wall thickness. A good correlation was found between the latter parameter and $t_{10 \%}$, i.e., the time to $10 \%$ release, for both polymer grades employed. On the basis of the overall results, the investigated technique was proven suitable for the manufacturing of an innovative pulsatile release platform.
\end{abstract}

KEY WORDS: capsular device; hydroxypropylcellulose (HPC); injection molding; oral drug delivery; pulsatile/delayed release.

\section{INTRODUCTION}

In the field of oral delivery, pulsatile/delayed release has received increasing attention because of its ideal suitability for meeting chronotherapeutic needs related to the night or early-morning exacerbation of high-morbidity pathologies such as bronchial asthma, rheumatoid arthritis, and cardiovascular disease (1-4). Due to the inherent capability of eliciting programmable lag phases prior to drug release, pulsatile delivery medications may indeed enable a timely onset of the therapeutic effect following evening dosing thus overcoming compliance issues possibly associated with inconvenient administration regimens.

Based on a time-dependent design strategy, which relies on the relatively consistent small intestinal transit of dosage forms, oral delayed delivery systems can also be exploited to target the colon for the local treatment of large bowel pathologies, such as inflammatory bowel disease, and the chemoprevention of colorectal adenocarcinoma (5-8). In addition, colonic release is extensively investigated with the aim of improving the bioavail-

\footnotetext{
${ }^{1}$ Dipartimento di Scienze Farmaceutiche "P. Pratesi", Università degli Studi di Milano, Via G. Colombo 71, 20133 Milan, Italy.

${ }^{2}$ To whom correspondence should be addressed. (e-mail: andrea. gazzaniga@unimi.it)
}

ability of orally administered peptides, proteins, oligonucleotides, and nucleic acids, which mostly exhibit poor intestinal stability and permeability characteristics $(9,10)$.

A variety of peroral formulations are described for pulsatile delivery purposes, including reservoir, capsular, and osmotic release platforms (1-3). Reservoirs, i.e., coated devices containing the active ingredient within an inner core, include in turn rupturable, swellable/erodible, and diffusive systems. These differ from each other in the physicochemical and functional characteristics of the coating material that is responsible for the control of release. Swellable/erodible devices are provided with a polymeric layer, e.g., composed of hydrophilic cellulose ethers, polyethylene oxide, xanthan gum, or sodium alginate, that undergo swelling, erosion, and/ or dissolution processes while in contact with aqueous fluids, thereby delaying the drug liberation until the core is reached by the solvent (1). Accordingly, the time to release can generally be programmed by selecting the proper nature and thickness of the polymeric coating applied.

The Chronotopic ${ }^{\mathrm{TM}}$ system is a swellable/erodible device based on hydrophilic cellulose derivatives, typically hydroxypropyl methylcellulose (HPMC), as the releasecontrolling agent and on tablet, gelatin capsule, or multiple units (mini-tablets, pellets) as the drug core (11-15). Its ability to yield reproducible lag phases prior to release was demonstrated both in vitro and in vivo on healthy volunteers. Provided with an enteric film, the system was 
Table I. Injection-Molding Process Conditions

\begin{tabular}{lcc}
\hline & Kluce $^{\circledR}$ LF & Klucel $^{\circledR}$ EF \\
\hline Temperature R1 $\left({ }^{\circ} \mathrm{C}\right)$ & 165 & 175 \\
Temperature R2 $\left({ }^{\circ} \mathrm{C}\right)$ & 160 & 170 \\
Temperature R3 $\left({ }^{\circ} \mathrm{C}\right)$ & 160 & 170 \\
Injection pressure (bar) & 80 & 110 \\
Injection time (s) & 15 & 15 \\
Cooling time (s) & 10 & 10 \\
Cooling temperature $\left({ }^{\circ} \mathrm{C}\right)$ & 25 & 25 \\
\hline
\end{tabular}

also proven to target the colon district on the basis of the aforementioned time-dependent formulation approach. The application of the functional cellulosic layer was successfully accomplished by various techniques, such as double compression, hydro-organic or aqueous spray coating, and powder layering. In particular, aqueous spray coating with a low-viscosity HPMC grade $\left(\right.$ Methocel $^{\circledR}$ E50) was demonstrated to offer an advantageous balance of key aspects such as feasibility, scalability, and pulsatile delivery performance (11,16-18). More recently, adequate stability and in vitro release characteristics were shown by Methocel ${ }^{\circledR}$ E50 spray-coated systems containing bovine insulin in the core tablet, with or without enzyme inhibitor and absorption enhancer compounds $(19,20)$.

Major technical and regulatory benefits could be anticipated if the core and the coat were handled as independent formulation items. A different configuration was accordingly proposed for swellable/erodible devices based on separate container shells and drug fillings (21-23). In these instances, the use of extrusion techniques was explored. On account of the established thermoplastic behavior combined with the availability in a range of viscosity grades, hydroxypropylcellulose (HPC) was employed besides HPMC as the release-controlling barrier polymer (24-26). Preliminary findings pointed out the feasibility of such techniques along with the potential of the obtained devices as an effective delayed release platform. Particularly injection molding, which involves the heating of thermoplastic materials and forcing of the resulting softened/
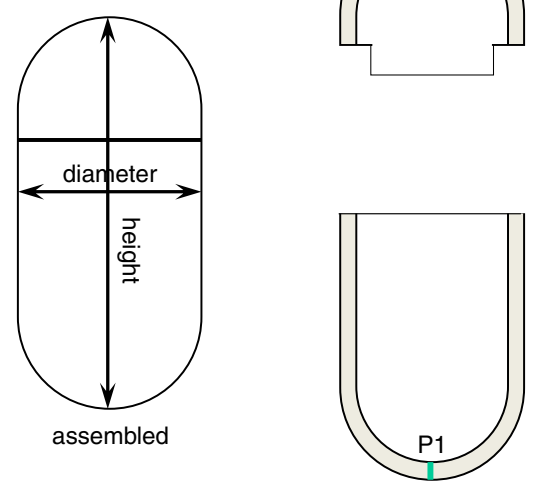

longitudinal capsule cross section
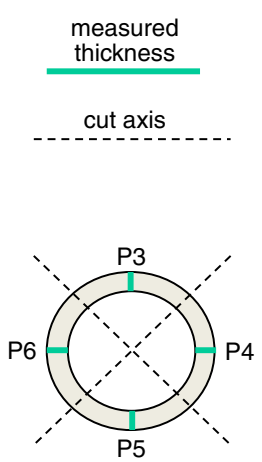

axial body cross section
Fig. 1. Outline of height, diameter, and thickness measurements performed on capsule shells
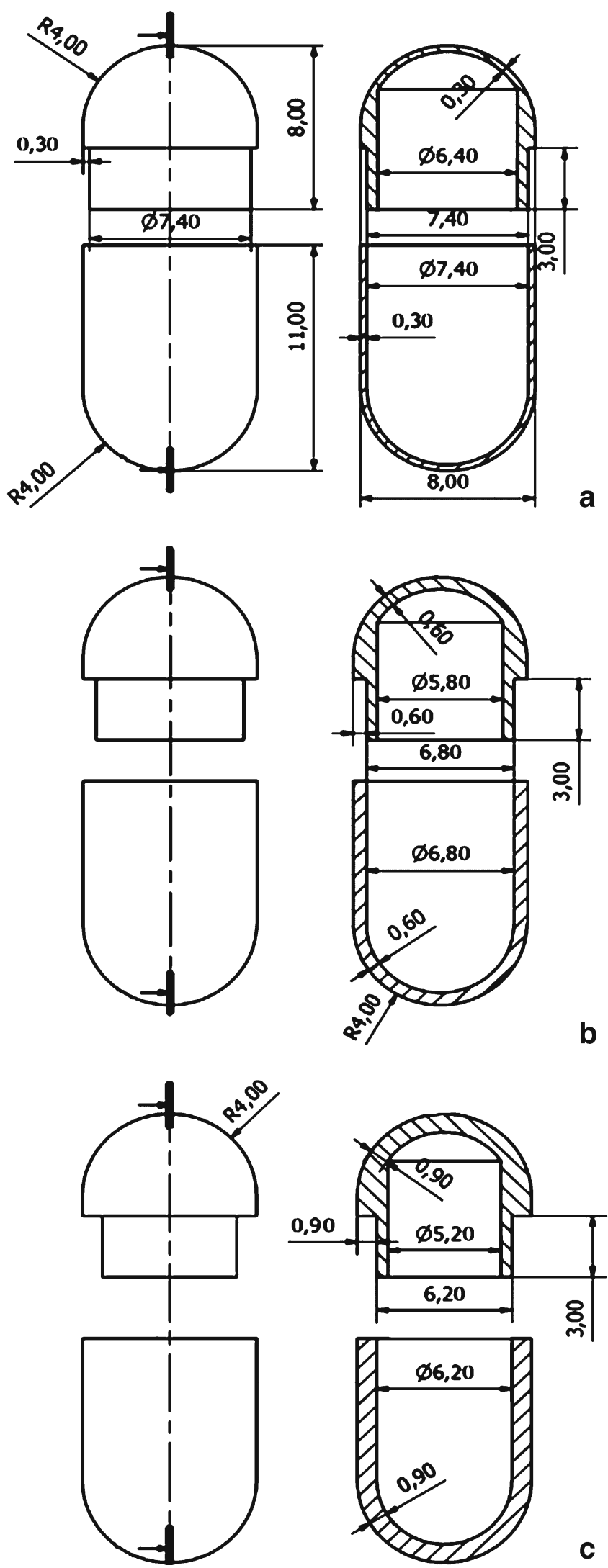

Fig. 2. Design of the mold for capsule shells with differing thicknesses 

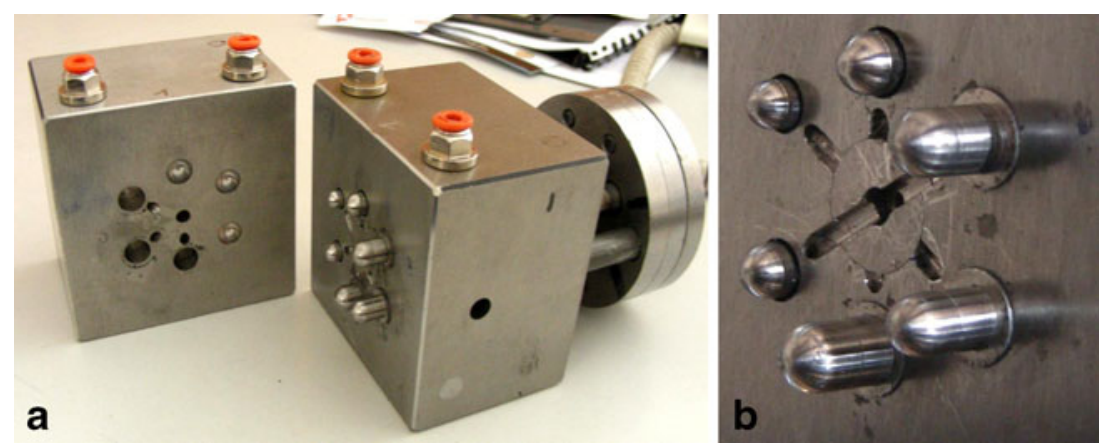

Fig. 3. Photograph of the mold for capsule shells with differing thicknesses (a) and details relevant to the injection orifice and adaptable pouring gate (b)

molten mass into a three-dimensional mold to be shaped while cooling and hardening, turned out worthy of more in-depth investigation because of the inherent versatility, scalability, and patentability prospects. In spite of a broad and long-lasting exploitation in the plastics industry, only a few interesting pharmaceutical applications are indeed reported (27-30).

Based on these premises, the aim of the present work was to design, prepare, and evaluate a novel injection-molded swellable/erodible device intended to convey differing formulations and release a variety of bioactive compounds following programmed lag phases. The peculiar advantages of such a device would lie in the possibility of undergoing an independent pharmaceutical development irrespective of the final contents and the scalability of the relevant manufacturing process.

\section{EXPERIMENTAL METHODS}

\section{Materials}

The materials were high-density polyethylene (HDPE; Hiplex ${ }^{\circledR}$ Type TR130, Petrohemija, Pančevo, Serbia), HPC (Klucel $^{\circledR}$ EF, LF, and GF, Aqualon, DE, USA; Eigenmann \& Veronelli, Italy), polyethylene glycol (PEG 1500, Clariant Masterbatches, Italy), and acetaminophen (C.F.M., Italy).

\section{Methods}

Injection-Molding Process. Blends of HPC 90\% and PEG $150010 \%(w / w)$ were prepared by mixing in Turbula (Type T2C, WAB, Switzerland) for $20 \mathrm{~min}$. Prior to use, the mixtures were dried in a ventilated oven at $40^{\circ} \mathrm{C}$ for at least $12 \mathrm{~h}$. Twenty-five grams of pre-treated powder mixture was successively loaded into the hopper of the injection-molding press (Baby Plast mod. 6/10P, Rambaldi S.r.l., Italy). After loading, the hopper was closed and dry nitrogen purge was maintained throughout the entire process. The powder material was transferred from the hopper into the plasticization unit (R1) and then conveyed by means of a piston (14 mm diameter) to the injection unit (R2), where it was press-injected through a 2mm-diameter nozzle (R3) into the mold cavity within a defined period of time. Before product ejection, the mold was kept closed to allow the processed materials to cool down and harden. The final operating conditions under which automated production cycles could be carried out with Klucel ${ }^{\circledR}$ LF and EF formulations are reported in Table I. The mold was manually lubricated with peanut oil approximately every 15-20 units manufactured. The first unit obtained after lubrication was discarded.

Water Vapor Sorption. Approximately 1-g samples (powder or capsule shells) were either stored under ambient conditions $\left(24 \pm 2^{\circ} \mathrm{C} / 55 \pm 5 \% \mathrm{RH}\right)$ or in closed glass containers maintained at room temperature and constant $\mathrm{RH}$ values of $0 \%$, $22 \%, 38 \%, 53 \%, 75 \%$, and $97 \%$, which were controlled with $\mathrm{P}_{2} \mathrm{O}_{5}$ and saturated aqueous solutions of $\mathrm{CH}_{3} \mathrm{COOK}, \mathrm{NaI}, \mathrm{Mg}$ $\left(\mathrm{NO}_{3}\right)_{2}, \mathrm{KNO}_{3}$, and $\mathrm{K}_{2} \mathrm{SO}_{4}$, respectively (31). $\mathrm{RH}$ was monitored by means of a calibrated hygrometer. Equilibrium was assumed to be reached when weight change between successive measurements was $<0.1 \%$. The water content was determined on 150-mg samples by Karl-Fischer titrimetry, employing a Mettler DL50 Graphix equipment (Mettler Toledo GmbH, Switzerland). The material to be analyzed was dissolved in anhydrous methanol, and the resulting solution was titrated with Hydranal ${ }^{\circledR}$ Composit 5 (Fluka Analytical, MO, USA). Moisture content was calculated as the \% ratio between the amount of water in the sample and its dry weight.

Capsule Shell Characterization. All measurements were performed after 7 days storage at ambient conditions from preparation. Assembled capsule shells were checked for weight (analytical balance BP211, Sartorius, Germany, $n=$ 20), height, and diameter (analogical micrometer CD15D, Mitutoyo, Japan, $n=10$ ). The wall thickness was determined in differing regions of separated body and cap items (digimatic indicator ID-C112X, Mitutoyo, Japan, $n=10$ ). Six positions were identified on each sample (P1-P6), where nominal thickness was expectedly obtained. Five positions were located on the body and only one on the cap. In particular, P1 and P2 were located on the semi-spherical

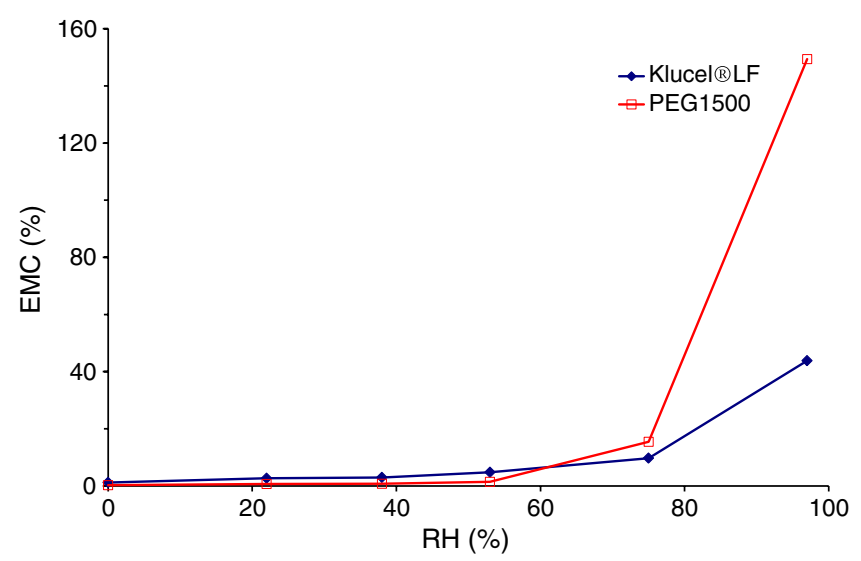

Fig. 4. EMC of Klucel ${ }^{\circledR}$ LF and PEG 1500 powders as a function of RH 


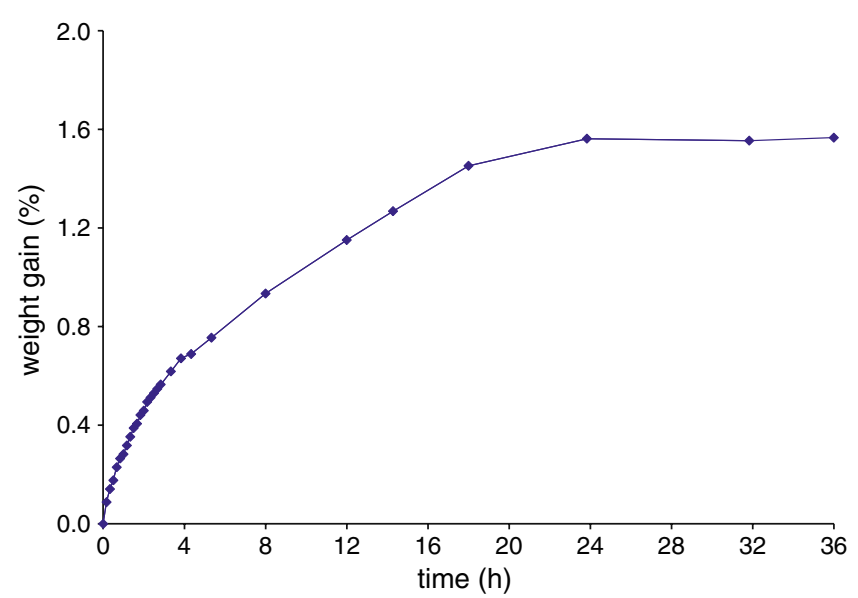

Fig. 5. Weight gain $v$ s. time curves of Klucel ${ }^{\circledR}$ LF/PEG $1500(10 \%$, $w / w)$ mixture under differing $\mathrm{RH}$ storage conditions

ends of body and cap, respectively, while P3-P6 were located in the cylindrical portion of the body, as indicated in Fig. 1. Thickness measurements required dissection of the molded sample.

The mechanical properties of assembled capsule shells were evaluated in comparison with hard-gelatin capsules (size 0 ) by means of a TA.HD. plus Texture Analyzer (Stable Micro Systems, UK, $n=3$ ). One-kg load cell and a flat-ended probe with $4 \mathrm{~mm}$ diameter were employed. The unit to be tested was placed on the lower platform so that the capsule body region between the junction area and semi-spherical end was centrally positioned under the probe (32). The probe was advanced onto the capsule at a compression rate of $0.1 \mathrm{~mm} / \mathrm{s}$. Elastic modulus (Newton per square millimeter) was calculated from the initial linear portion of stress vs. strain curves.
Evaluation of the Capsular Device Performance. Each capsule body was manually filled with $80 \mathrm{mg}$ acetaminophen powder $\left(d_{90}=50 \mu \mathrm{m}\right)$ and closed with a matching cap. The assembled devices were sealed by applying a 3\% $(w / v)$ Klucel $^{\circledR}$ EF aqueous solution on the body/cap junction area and then kept at ambient conditions for at least $1 \mathrm{~h}$ to allow the sealing film to dry.

The morphological changes undergone by the capsular devices when exposed to aqueous fluids were evaluated on units immersed in unstirred deionized water at the temperature of $37 \pm 0.5^{\circ} \mathrm{C}$. Digital photographs were taken at successive time points.

For the release test $(n=3)$, a three-position USP31 disintegration apparatus was used (18). Each unit was inserted in a basket-rack assembly so that only one of the six available tubes was occupied. The basket-rack assemblies moved at 31 cycles/min rate in separate vessels containing $900 \mathrm{~mL}$ water at $37 \pm 0.5^{\circ} \mathrm{C}$. Fluid samples were withdrawn at fixed time points and assayed spectrophotometrically $(248 \mathrm{~nm})$. Release tests were repeated after 6 months storage of empty capsule shells in sealed plastic bags at $25 \pm 5^{\circ} \mathrm{C}$ and $60 \pm 5 \%$ RH (Espec LHL-113 stability testing chamber, Seneco, Italy).

\section{RESULTS AND DISCUSSION}

The device under investigation was designed in the form of a capsular shell consisting of matching body and cap items that could be joined together after filling with formulations of different kinds. Once assembled, the body and cap components were expected not to entail any junction gap so that a plane external surface could be obtained. Such a device should meet the size requirements of oral dosage forms and present shape as well as mechanical characteristics suitable for established filling and post-filling pharmaceutical proce-

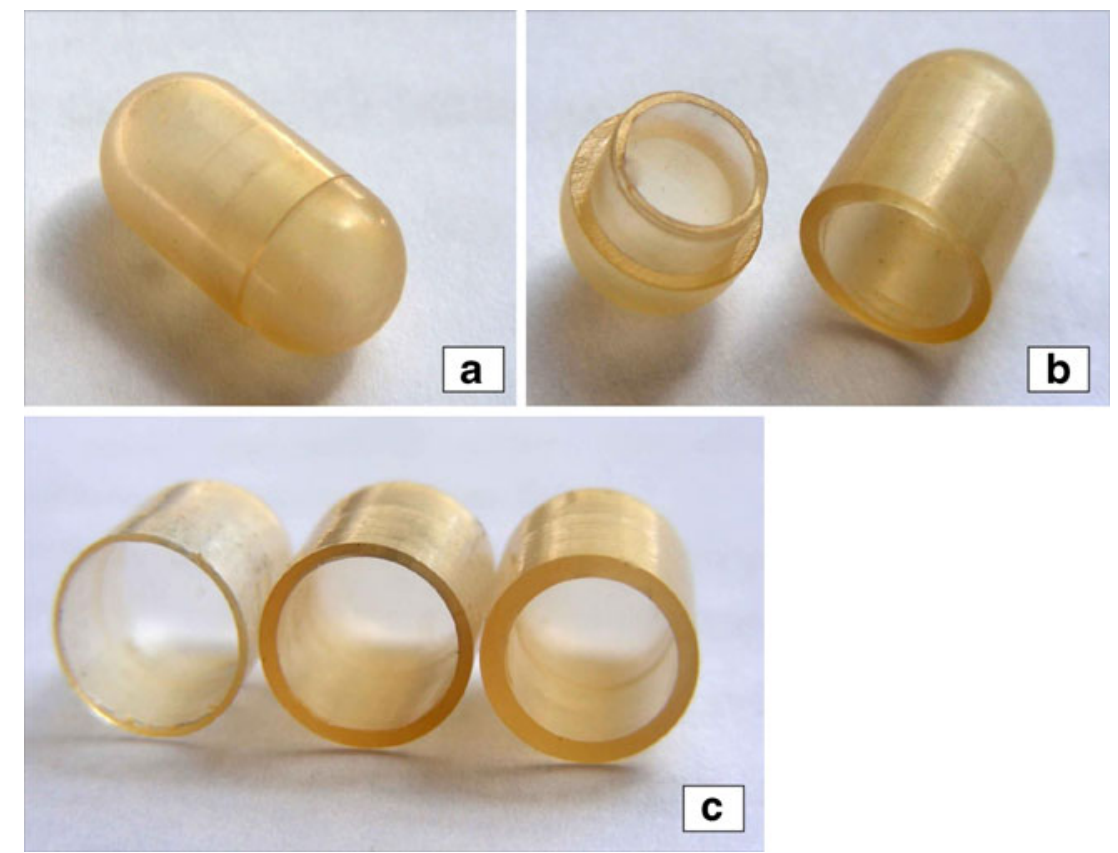

Fig. 6. Photographs of a Klucel ${ }^{\circledR}$ LF-based capsule shell with $900 \mu \mathrm{m}$ nominal thickness $(\mathbf{a}, \mathbf{b})$ and of $\mathrm{Klucel}^{\circledR}$ LF-based capsule bodies with 300, 600, and $900 \mu \mathrm{m}$ nominal thickness (c) 


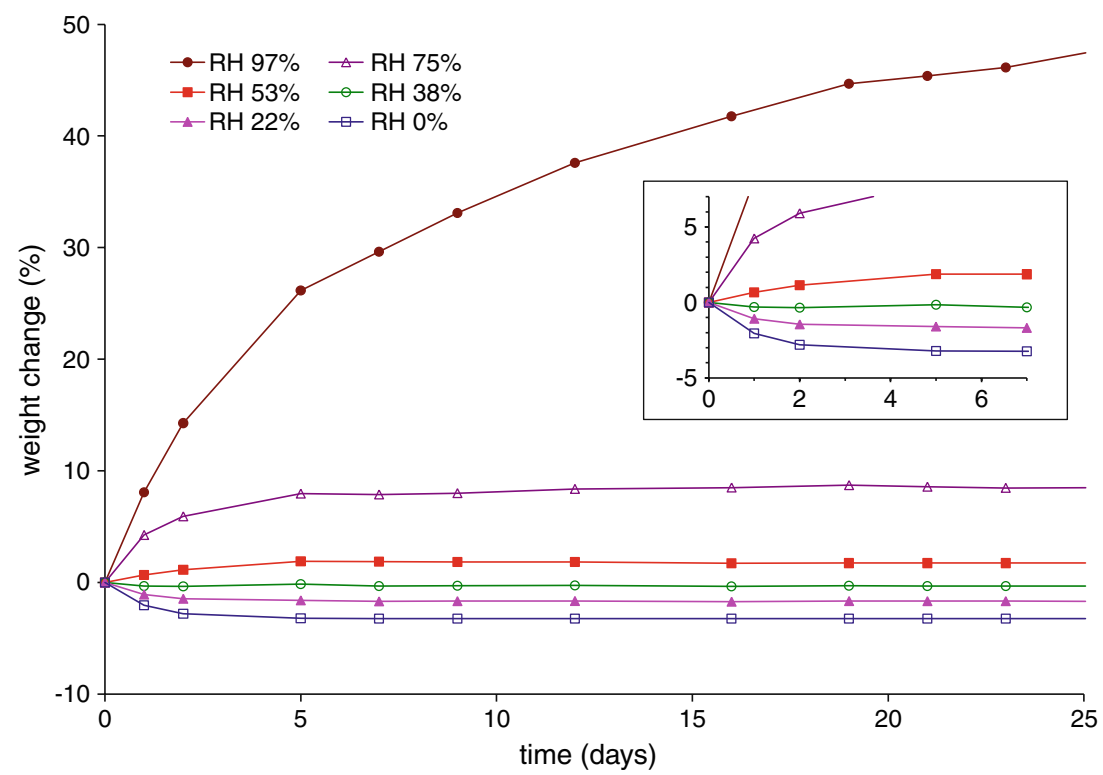

Fig. 7. Weight change vs. time curves of Klucel ${ }^{\circledR}$ LF-based capsule shells under differing $\mathrm{RH}$ conditions (detail relevant to the first 7 days in frame)

dures (e.g., coating, packaging). The shell wall needed to be adjustable within a defined thickness range in order to provide delay phases of differing durations. Moreover, an effective though uncomplicated locking mechanism was sought, possibly based on the mutual pressure exerted by the contact areas of matching items only.

Hence, a mold intended to be coupled with the benchtop injection-molding press in use was purposely designed to fulfill of the above-mentioned endpoints. As the starting mold prototype, this was conceived to enable the preparation of matching caps and bodies within a single manufacturing cycle and the selection of differing shell thicknesses. Based on the experience previously gained in the use of hydrophilic cellulose ethers as release-delaying agents, nominal thicknesses of 300, 600, and $900 \mu \mathrm{m}$ were pursued (Figs. 2 and 3). Such values applied to the thinner wall areas, e.g., the regions where body and cap were not overlapped because of the locking system.

In order to test the performance of the bench-top injection-molding press when coupled with the newly designed mold, preliminary trials were carried out with HDPE, which was selected because of the well-established extrudability and commercial availability in the form of granules with excellent flow properties. Such trials were aimed at exploring the impact of the main process parameters, identifying the especially critical ones, and highlighting possible serial manufacturing defects. The mutual interdependence of most parameters was thereby demonstrated along with the possibility of conducting fully automated production cycles.

The use of hydrophilic cellulose derivatives, which would impart the desired functionality to the molded capsule shells, was thus attempted. Due to the adequate processability exhibited by HPC in hot-melt extrusion, differing viscosity grades of this polymer were employed as the releasecontrolling/container-forming material, i.e., Klucel ${ }^{\circledR} \mathrm{EF}, \mathrm{LF}$, and GF (24-26). The addition of a plasticizer was necessary in all cases. Particularly, PEG 1500 in the amount of $10 \%(w / w)$ offered an acceptable balance between extrudability of the polymeric substrate and mechanical properties of the molded units. Klucel ${ }^{\circledR} \mathrm{GF}$, however, involved major feasibility issues because of the high viscosity of its mixtures. Plasticized HPC required operating temperatures in the $160-180^{\circ} \mathrm{C}$ range irrespective of viscosity grade.

The water content of the HPC/PEG 1500 mixtures turned out to strongly impact on the process outcome. Indeed, manufacturing defects such as voids observed within the extruded units were ascribed to excessive moisture levels of the starting materials, in agreement with previous findings regarding the effect of water on injection-molded products $(33,34)$. Therefore, the humidity of HPC and PEG 1500 powders needed to be strictly controlled. For this purpose,

Table II. Technological Characteristics of Klucel ${ }^{\circledR}$ LF-Based Capsule Shells with Different Nominal Thickness (CV in brackets)

\begin{tabular}{ccccc}
\hline Nominal thickness, $\mu \mathrm{m}$ & Weight, mg & Height, mm & Diameter, mm & Thickness, $\mu \mathrm{m}$ \\
\hline 300 & $238(0.84)$ & $16.08(0.24)$ & $8.18(0.37)$ & $346(12.30)$ \\
600 & $336(0.70)$ & $16.08(0.12)$ & $8.19(0.37)$ & $645(13.20)$ \\
900 & $417(0.57)$ & $16.08(0.09)$ & $8.20(0.24)$ & $880(4.64)$ \\
\hline
\end{tabular}

$C V$ coefficient of variation 


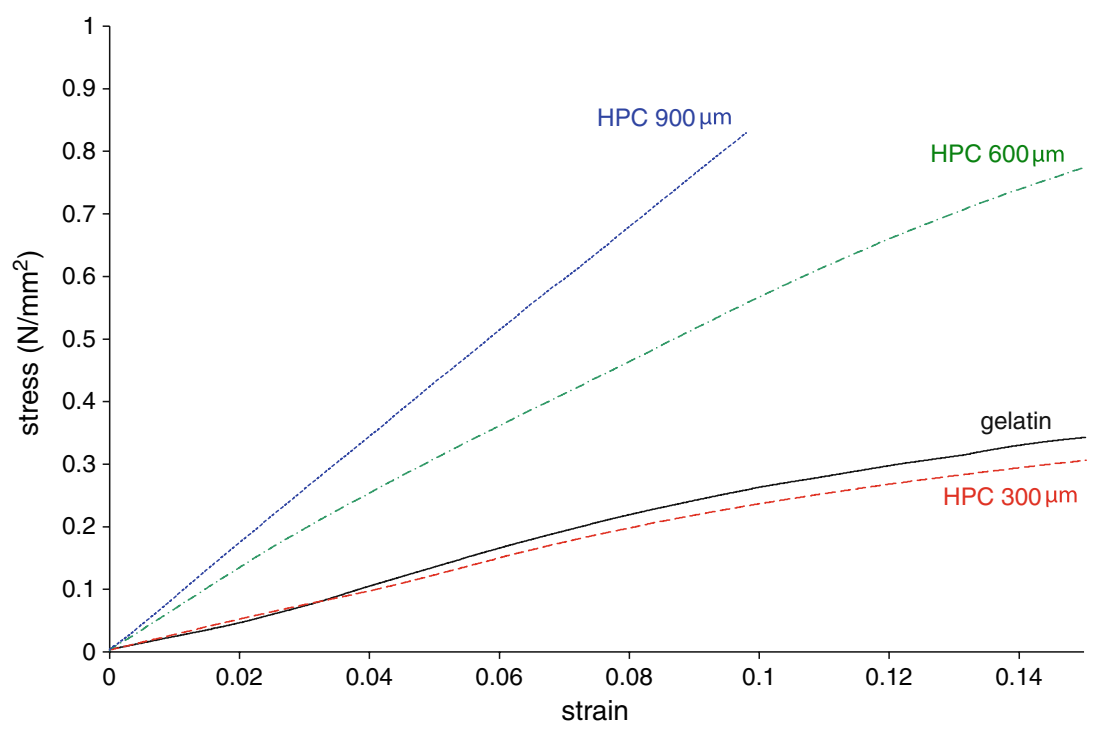

Fig. 8. Stress $v s$. strain curves of Kluce $~^{\circledR}$ LF-based capsule shells with differing thicknesses and hard-gelatin capsules

the relevant moisture content and water sorption/desorption behavior were evaluated $(35,36)$. The moisture content of Klucel $^{\circledR}$ LF and the plasticizer as received, assessed immediately after withdrawal from sealed packages, were approximately $2.5 \%$ and $1.5 \%$, respectively. Figure 4 shows the equilibrium moisture content (EMC) profiles of such materials stored at the temperature of $24 \pm 2^{\circ} \mathrm{C}$ as a function of RH. While no major changes were observed up to $55 \%$ RH, a marked increase in the EMC of both Klucel ${ }^{\circledR}$ LF and PEG 1500 occurred beyond $75 \%$ RH. Analogous results were obtained in the case of Klucel ${ }^{\circledR} \mathrm{EF}$ and GF (data not shown). The need for a drying step prior to injection molding was thus highlighted. On the basis of the melting temperature of PEG 1500 and of preliminary trials, the formulations were subjected to a minimum 12-h thermal pre-treatment in a ventilated oven at $40^{\circ} \mathrm{C}$, which led to a reduction of the water content to $0.8 \%$. Under ambient conditions $\left(24 \pm 2^{\circ} \mathrm{C} / 55 \pm 5 \%\right.$ $\mathrm{RH}), \mathrm{HPC} /$ plasticizer mixtures took up their initial moisture within $24 \mathrm{~h}$ (Fig. 5). The presence of PEG 1500 was proven not to affect the water re-uptake kinetics of HPC. In an attempt to slow down the re-uptake process during operation, relatively small amounts of pre-treated mixture were successively loaded into the hopper, so that the substrate would reside in the press no longer than $30 \mathrm{~min}$. After loading, the hopper was closed and dry nitrogen purge was started. By such a procedure, a moisture content threshold of $1.2 \%$ was not exceeded.

When HPC was employed, the process turned out more difficult than in the case of HDPE mainly because of the inherent viscosity and tackiness characteristics of molten polymer. These resulted in the need for higher injection pressures and in difficulties encountered when removing the products from the mold. Moreover, the substrate tended to undergo browning phenomena, thus limiting the chances of reducing viscosity by raising the temperature. Following proper selection of process parameters with the Klucel ${ }^{\circledR}$ LF formulation, however, automated production cycles could be carried out (15-20 units produced), which required interruptions approximately every $20 \mathrm{~min}$ for manual mold lubrication. Capsular shells with nominal thickness of 300 , 600, and $900 \mu \mathrm{m}$ were thus prepared (Fig. 6). The visual inspection of such units revealed the presence of a welding line opposite the injection orifice position of capsule bodies. In most instances, this defect was restrained to the shell surface. The line was deeper or even extended across the whole wall thickness in a limited number of capsules only.

Due to the previously highlighted tendency of dried HPC to water uptake, the weight of molded units was monitored over time under increasing RH storage conditions (Fig. 7). The obtained results showed that, when RH was in the 0$75 \%$ range, a constant weight was reached within 5 days.

Capsule shells were characterized in terms of mass, dimensions, thickness, and mechanical properties (Table II). In order to allow for re-equilibrium with ambient humidity, all measurements were performed after 7 days storage at ambient conditions RH from preparation. Weight, diameter, and height as determined on assembled shells were in a relatively narrow range, thus pointing out the reliability of the manufacturing process. Higher variability was shown by the wall thickness, which was assessed by averaging the results of a set of measurements effected in fixed regions of the body and cap items, respectively. Because it was not reflected in weight data, the variability in thickness was attributed to the way the melted substrate spread inside the mold upon injection rather than to a poorly reproducible injected volume. As the cavity of capsule bodies was formed by the insertion of a punch, minor shifts of the latter were indeed hypothesized to occur in process, e.g., as a consequence of the injection pressures needed.

Elastic modulus (EM), calculated from the initial linear portion of the stress $v s$. strain curves, was chosen to describe the mechanical characteristics of assembled capsule shells (Fig. 8; Table II) (32). EM data were demonstrated to increase as a function of thickness. When tested by the same method, hard-gelatin capsules interestingly exhibited EM values comparable to those of the molded units with $300 \mu \mathrm{m}$ 

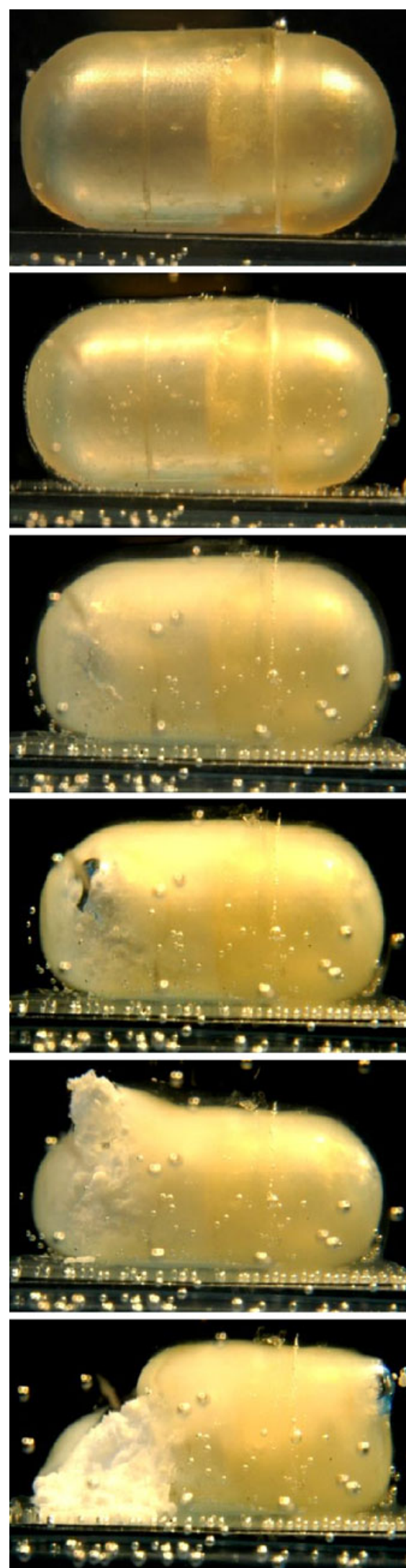

Fig. 9. Photographs taken at successive time points of a Klucel ${ }^{\circledR}$ LFbased capsular device (600 $\mu \mathrm{m}$ nominal thickness) immersed in deionized water without stirring

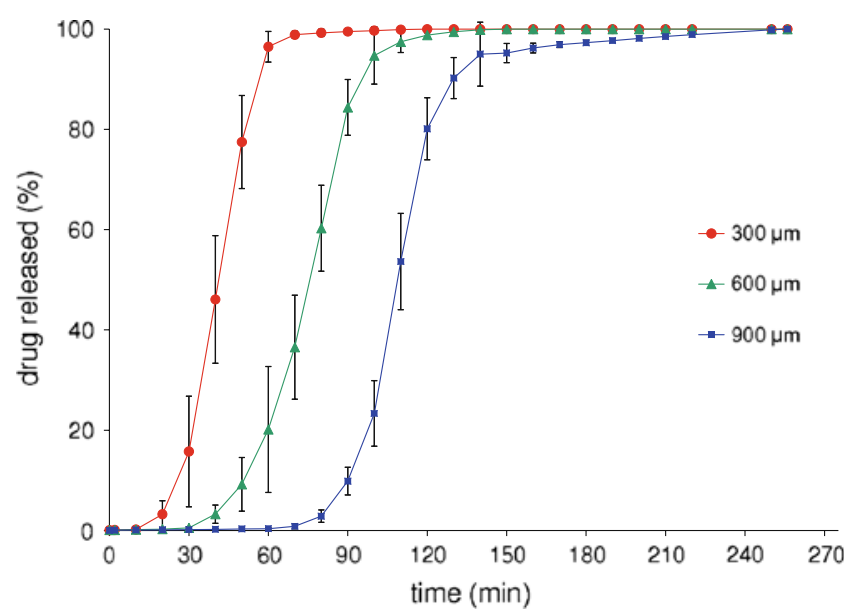

Fig. 10. Average in vitro release profiles of acetaminophen from Klucel ${ }^{\circledR}$ LF-based capsular devices with differing shell thicknesses (bars indicate standard deviation)

nominal thickness. This might indicate that the stresses associated with normal handling or brought about by filling, coating, and packaging procedures would hardly result in impaired integrity of the container device under investigation.

Subsequently, the morphological changes undergone by HPC shells in aqueous fluids were evaluated along with their ability to defer the liberation of the contents. By way of example, a sequence of photographs of a $600-\mu \mathrm{m}$ Klucel ${ }^{\circledR}$ LFbased capsule filled with a tracer drug powder and immersed in deionized water without stirring is displayed in Fig. 9. Initially, the formation of a swollen polymeric barrier could be observed. As the polymer dissolved into the medium, the semi-spherical ends of the shell, i.e., regions were body and cap are not overlapped, became thinner until rupture and liberation of the inner powder. Notably, such a breakage mode was consistently verified.

Reproducible in vitro pulsatile release patterns were obtained from these devices, which could suggest that the variability encountered in the wall thickness would not exert a major impact on their performance (Fig. 10). In particular, the whole drug load was released after lag times that

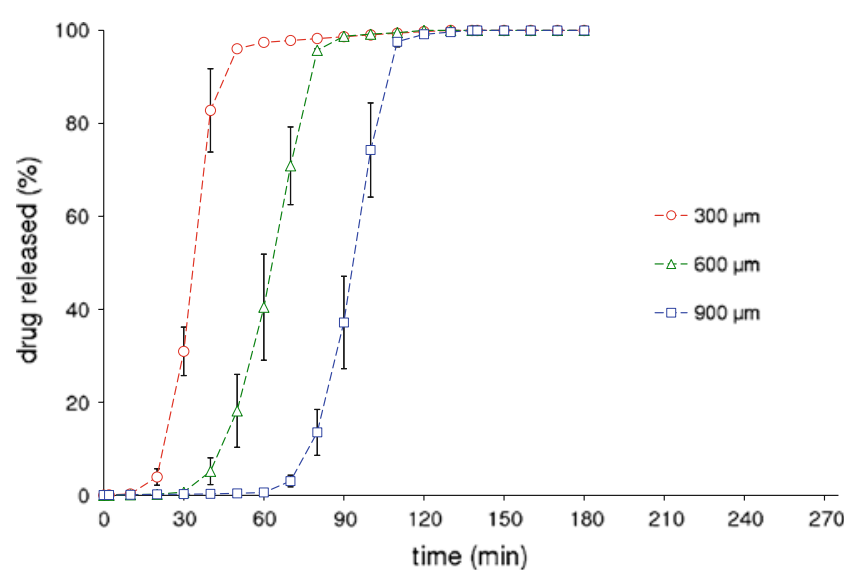

Fig. 11. Average in vitro release profiles of acetaminophen from Klucel ${ }^{\circledR}$ EF-based capsular devices with differing shell thicknesses (bars indicate standard deviation) 


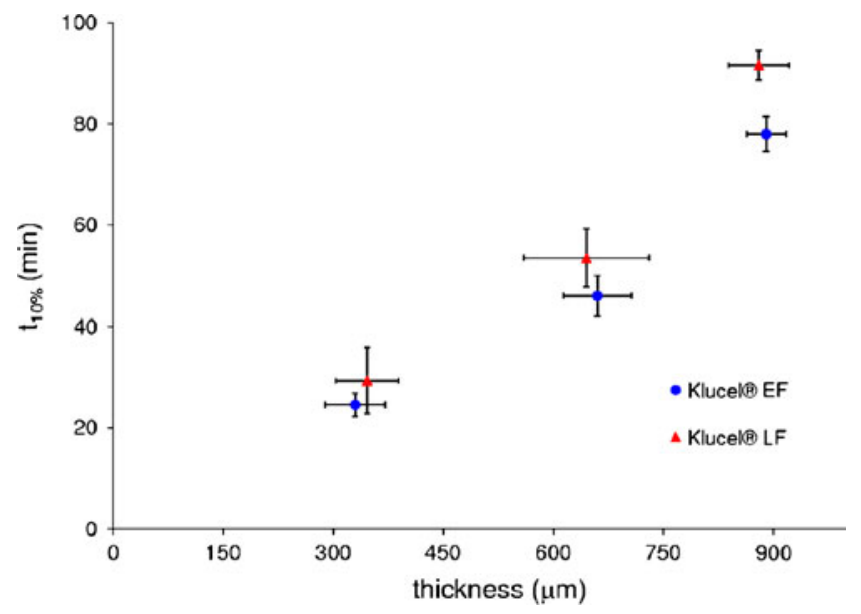

Fig. 12. In vitro lag time $\left(t_{10 \%}\right)$ vs. wall thickness relationship for capsular devices with differing shell compositions

increased as a function of thickness. The delay, expressed as the time to $10 \%$ release $\left(t_{10 \%}\right)$, was significantly different $(p<$ 0.05 ) for capsules of all nominal thicknesses.

Devices based on Klucel ${ }^{\circledR}$ EF with same nominal thicknesses, successfully manufactured after adjusting the process parameters set up with the Klucel ${ }^{\circledR}$ LF formulation, provided analogous release profiles (Fig. 11). Also in this case, significantly different $(p<0.05) t_{10 \%}$ values were found for 300,600 , and $900 \mu \mathrm{m}$ capsule shells.

A good relationship between thickness and $t_{10 \%}$ was found for both HPC grades, thus indicating that the delay prior to drug liberation could be programmed according to differing needs (Fig. 12). When comparing Klucel ${ }^{\circledR}$ LF and $\mathrm{EF}$ units, differences in $t_{10 \%}$ were found in agreement with the polymer viscosity, which were significant $(p<0.05)$ at $900 \mu \mathrm{m}$ nominal thickness. Finally, a preliminary stability study pointed out that 6 months storage at ambient conditions of empty capsule shells did not alter the release performance of the resulting Klucel ${ }^{\circledR}$ LF-based devices (Table III).

\section{CONCLUSIONS}

Oral capsular shells intended for a time-controlled delivery of drugs based on the swelling/erosion of HPC as the release-controlling mechanism were successfully prepared by injection molding. Satisfactory results were obtained in terms of process feasibility and release as well as stability characteristics of the molded devices, thus pointing out the potential suitability of the investigated technique for the

Table III. Initial and After 6 Months Storage Lag Time $\left(t_{10 \%}\right)$ Obtained from of Klucel ${ }^{\circledR}$ LF-Based Capsular Devices

\begin{tabular}{ccc}
\hline \multirow{2}{*}{ Nominal thickness $(\mu \mathrm{m})$} & \multicolumn{2}{c}{$t_{10 \%}(\mathrm{~min} ; \mathrm{SD})$} \\
\cline { 2 - 3 } & Initial & $t=6$ months \\
\hline 300 & $29.3(6.5)$ & $27.2(7.4)$ \\
600 & $53.5(5.7)$ & $54.8(3.8)$ \\
900 & $91.7(2.9)$ & $87.4(5.0)$ \\
\hline
\end{tabular}

$S D$ standard deviation manufacturing of an innovative pulsatile delivery platform. Future research efforts will be aimed at the improvement of the mold configuration, so that the variability in the shell thickness could be limited, and of the automation extent of the manufacturing process.

\section{REFERENCES}

1. Gazzaniga A, Palugan L, Foppoli A, Sangalli ME. Oral pulsatile delivery systems based on swellable hydrophilic polymers. Eur J Pharm Biopharm. 2008;68:11-8.

2. Maroni A, Zema L, Cerea M, Sangalli ME. Oral pulsatile drug delivery systems. Expert Opin Drug Deliv. 2005;2:855-71.

3. Bussemer T, Otto I, Bodmeier R. Pulsatile drug-delivery systems. Crit Rev Ther Drug Carrier Syst. 2001;18:433-58.

4. Youan B-BC. Chronopharmaceutics: gimmick or clinically relevant approach to drug delivery? J Control Release. 2004;98:337-53.

5. Davis SS. The design and evaluation of controlled release systems for the gastro-intestinal tract. J Control Release. 1985;2:27-38.

6. Gazzaniga A, Maroni A, Sangalli ME, Zema L. Time-controlled oral delivery systems for colon targeting. Expert Opin Drug Deliv. 2006;3:583-97.

7. Gazzaniga A, Giordano F, Sangalli ME, Zema L. Oral colonspecific drug delivery: design strategies. STP Pharma Pratiques. 1994;4:336-43.

8. Takayama T, Goji T, Taniguchi T, Inoue A. Chemoprevention of colorectal cancer-experimental and clinical aspects. J Med Investig. 2009;56:1-5.

9. Bourgeois S, Harvey R, Fattal E. Polymer colon drug delivery systems and their application to peptides, proteins, and nucleic acids. Am J Drug Deliv. 2005;3:171-204.

10. Haupt S, Rubinstein A. The colon as a possible target for orally administered peptide and protein drugs. Crit Rev Ther Drug Carrier Syst. 2002;19:499-551.

11. Sangalli ME, Maroni A, Zema L, Cerea M, Gazzaniga A. The Chronotopic $^{\mathrm{TM}}$ technology. In: Youan B-BC, editor. Chronopharmaceutics. Hoboken: Wiley; 2009. p. 145-63.

12. Sangalli ME, Maroni A, Zema L, Busetti C, Giordano F, Gazzaniga A. In vitro and in vivo evaluation of an oral system for time and/or site-specific drug delivery. J Control Release. 2001;73:103-10.

13. Gazzaniga A, Sangalli ME, Giordano F. Oral Chronotopic ${ }^{\circledR}$ drug delivery systems: achievement of time and/or site specificity. Eur J Pharm Biopharm. 1994;40:246-50.

14. Gazzaniga A, Iamartino P, Maffione G, Sangalli ME. Oral delayed-release system for colonic specific delivery. Int J Pharm. 1994;108:77-83.

15. Maffione G, Iamartino P, Guglielmini G, Gazzaniga A. Highviscosity HPMC as a film-coating agent. Drug Dev Ind Pharm. 1993;19:2043-53.

16. Zema L, Maroni A, Foppoli A, Palugan L, Sangalli ME, Gazzaniga A. Different HPMC viscosity grades as coating agents for an oral time and/or site-controlled delivery system: an investigation into the mechanisms governing drug release. J Pharm Sci. 2007;96:1527-36.

17. Sangalli ME, Maroni A, Foppoli A, Zema L, Giordano F, Gazzaniga A. Different HPMC viscosity grades as coating agents for an oral time and/or site-controlled delivery system: a study on process parameters and in vitro performances. Eur J Pharm Sci. 2004;22:469-76.

18. Gazzaniga A, Busetti C, Moro L, Sangalli ME, Giordano F. Time-dependent oral delivery systems for colon targeting. STP Pharma Sciences. 1995;5:83-8.

19. Maroni A, Del Curto MD, Serratoni M, Zema L, Foppoli A, Gazzaniga A, et al. Feasibility, stability and release performance of a time-dependent insulin delivery system intended for oral colon release. Eur J Pharm Biopharm. 2009;72:246-51.

20. Del Curto MD, Maroni A, Foppoli A, Zema L, Gazzaniga A, Sangalli ME. Preparation and evaluation of an oral delivery system for time-dependent colon release of insulin and selected protease inhibitor and absorption enhancer compounds. J Pharm Sci. 2009;98:4661-9. 
21. Gazzaniga A, Cerea M, Cozzi A, Foppoli A, Sangalli ME, Zema $\mathrm{L}$, inventors. Pharmaceutical dosage forms for time-specific drug delivery. European Patent WO 2010/009891 A. 2010.

22. Foppoli A, Cerea M, Zema L, Palugan L, Di Pretoro G, Sangalli ME, et al. Feasibility study on the use of extrusion techniques in the preparation of oral pulsatile delivery systems based on swellable/erodible polymers. Transactions of the 36th Annual Meeting of Controlled Release Society, 2009 July 18-22, Copenhagen, DK; 2009.

23. Gazzaniga A, Cerea M, Cozzi A, Foppoli A, Zema L, Maroni A, et al. Injection-molded swellable/erodible capsular devices intended for oral pulsatile delivery. Transactions of the 36th Annual Meeting of Controlled Release Society, 2009 July 18-22, Copenhagen DK; 2009.

24. Repka MA, Prodduturi S, Stodghill SP. Production and characterization of hot-melt extruded films containing clotrimazole. Drug Dev Ind Pharm. 2003;29:757-65.

25. Repka MA, McGinity JW. Physical-mechanical, moisture absorption and bioadhesive properties of hydroxypropylcellulose hot-melt extruded films. Biomaterials. 2000;21:1509-17.

26. Repka MA, Gerding TG, Repka SL, McGinity JW. Influence of plasticizers and drugs on the physical-mechanical properties of hydroxypropylcellulose films prepared by hot-melt extrusion. Drug Dev Ind Pharm. 1999;25:625-33

27. Quinten T, Gonnissen Y, Adriaens E, Beer TD, Cnudde V, Masschaele B, et al. Development of injection moulded matrix tablets based on mixtures of ethylcellulose and low-substituted hydroxypropylcellulose. Eur J Pharm Sci. 2009;37:207-16.
28. Vilivalam VD, Illum L, Iqbal K. Starch capsules: an alternative system for oral drug delivery. Pharm Sci Technol Today. 2000;3:64-9.

29. Rothen-Weinhold A, Besseghir K, Vuaridel E, Sublet E, Oudry $\mathrm{N}$, Kubel $\mathrm{F}$, et al. Injection-molding versus extrusion as manufacturing technique for the preparation of biodegradable implants. Eur J Pharm Biopharm. 1999;48:113-21.

30. Stepto RFT. Thermoplastic starch and drug delivery capsules. Polym Int. 1997;43:155-8.

31. Nyqvist $H$, Nicklasson $M$. The effect of water sorption on physical properties of tablets containing microcrystalline cellulose. Int J Pharm Technol Prod Manuf. 1983;4:67-73.

32. Missaghi S, Fassihi R. Evaluation and comparison of physicomechanical characteristics of gelatine and hypromellose capsules. Drug Dev Ind Pharm. 2006;32:829-38.

33. Eastman. Tenite cellulosic plastics-injection molding. 2002. http://www.eastman.com/Products/Pages/Product_Selector.aspx. Accessed 30 Jul 2010.

34. Michael Day Enterprises, Inc. Injection molding troubleshooting guide. 2010. http://www.mdayinc.com/guides/guides.php. Accessed 30 Jul 2010.

35. Prodduturi S, Manek RV, Kolling WM, Stodghill SP, Repka MA. Water vapor sorption of hot-melt extruded hydroxypropyl cellulose films: effect of physico-mechanical properties, release characteristics, and stability. J Pharm Sci. 2004;93:3047-56.

36. Alvarez-Lorenzo C, Gómez-Amoza JL, Martínez-Pacheco R, Souto C, Concheiro A. Interaction between hydroxypropylcelluloses and vapour/liquid water. Eur J Pharm Biopharm. 2000;50:307-18. 